\title{
Can there be Conceptual Dance?
}

\author{
By Anna Pakes
}

Midwest Studies in Philosophy, Issue on Philosophy of Dance, 2019

French choreographer Jérôme Bel's 1995 work Jérôme Bel begins when an older, naked woman walks on to the darkened stage carrying an illuminated light bulb. She walks to the back of the stage and writes the name "Thomas Edison" in chalk on the back wall. A second female performer - also naked - then moves to the back wall to write "Stravinsky, Igor" in chalk in the top right corner. She turns to face the audience and begins to hum the opening of Stravinsky's music for The Rite of Spring. Two further naked dancers make their appearance, writing their own names (Claire Haenni and Seguette, Frédéric) on the back wall, followed by some vital statistics - size, weight, age, bank balance and telephone number. As the work develops, the performers explore their naked bodies, pulling and stretching at the skin, creating weird shapes and images with different body parts thus distorted. Progress is slow - even painfully so. Not much seems to happen, and what does deliberately eschews the dynamics of climax and release. Towards the end, two of the performers urinate on stage, scoop up the urine with their hands and use it to rub out the inscriptions on the blackboard wall. The only lighting throughout is provided by the single light bulb, the only sound made by the dancers themselves (Yseult Roch sings her way through the whole of Stravinsky's score). There are no costumes, just the bare bodies of the performers. Bel describes the work as returning to the degree zero of dance through exploration of its basic elements: body, sound, light, presented on stage in front of an audience. ${ }^{1}$

This piece - along with other choreography by Bel - is often described as a work of "Conceptual Dance", a term used to denote a distinctive kind of contemporary choreography. So-called Conceptual Dance has precedents in in earlier work, particularly American postmodern choreography emerging from the Judson Dance Theater, one influence on Bel and his fellow artists. ${ }^{2}$ But the term "Conceptual Dance" is associated mainly with European choreographers, including Bel, Xavier Le Roy, Boris Charmatz, Vera Mantero, Jonathan Burrows and Tino Sehgal. These artists offer a reflexive engagement with the task of choreography, questioning its premises and results. They tend to eschew conventional dance virtuosity and choreographic structures. They often replace or supplement choreographed movement with dancers speaking or interacting with various kinds of object or text. They also foreground the real encounter between dancers and spectators in the moment of performance, breaking the "fourth wall" by disrupting or refusing the pretence of

\footnotetext{
${ }^{1}$ See Siegmund 1998 and Lepecki 2006: 49-51. Jérôme Bel was first performed in Brussels at the Brigittines international festival, on $1^{\text {st }}$ September 1995. See the choreographer's website for a full list of its several performances over many years: http://www.jeromebel.fr (under Performances / Jérôme Bel (1995) / Archive). The description here is based on my viewing of the work on film, specifically of a recorded performance in Ghent in December 1998. The film is available to view in various libraries and resource centres internationally: these are listed again on Bel's website (under Videos / Videos available in libraries). For further discussion and anlaysis of the work, see Bauer (2010b).

2 Judson Dance Theater was a collective of choreographers who presented their work in the 1960s at Judson Memorial Church in Greenwich Village, New York City. It has become synonymous with American post-modern dance, which challenged the artistic agenda and strategies of modern choreographers such as Doris Humphrey and Martha Graham. See Banes (1983).
} 
representation. This and other strategies critique the conventions of theatre dance, on which these artists offer ironic commentary.

Application of the term "Conceptual Dance" to these artists" work is controversial, however. The artists themselves often object to it: the term has "never [been] used in a programmatic way by makers of this work" (Cvejić 2014 [2005], 145), with several publicly (sometimes irritably) denying its appropriateness. ${ }^{3}$ Various reasons are cited. For some, the term has negative connotations and is problematic in setting the spectator up to find the work complicated, obtuse and dryly intellectual ( $T$ 'Jonck 2004). For others, it suggests the imposition of abstract ideas on movement or performance, ignoring their physical aspects in favour of the purely cerebral, despite the fact that this choreography often emphasises the materiality of the body and of performance (Burt 2017, 10). The contentious nature of the term means that its use is often accompanied by scare quotes. But that use nonetheless persists, perhaps because of a lack of plausible alternative terminology that captures what is distinctive about this choreographic mode. Calling it "experimental" or "avantgarde choreography" is too vague, and the time-indexing of the term "new dance" presents a further problem ("new dance" is also used to refer to contemporary dance of the late 1970s and 1980s, before the advent of "Conceptual Dance"). In this sense, the term has a positive value in identifying choreography with a conceptualist approach, pointing to certain affinities to Conceptual Art practice of the late 1960s and early 1970s and to subsequent work in similar mould (Cvejić 2014 [2005]; Fabius 2012).

My central aim here is not to take a stand on the controversy around the term "Conceptual Dance", although what follows does reflect back on these debates. I am concerned rather to investigate whether the term implies a kind of conceptual error, even a category mistake - whether it is possible that there could be such a thing as Conceptual Dance. This question arises because it is difficult to reconcile that possibility with one influential way of theorising conceptual art - the "idea idea" articulated by philosophers Peter Goldie and Elisabeth Schellekens (2010) and arguably embedded in prominent conceptual artists' discourse and practice. According to the idea idea, conceptual art has no physical medium, its medium being ideas as such. This poses a problem for the notion of Conceptual Dance which, in making reference to a particular art form, invokes precisely the sort of medium specificity that the idea idea explicitly rejects. It makes little sense to classify types of conceptual art according to art form, or the medium they employ, if conceptual art is not bound to a physical medium at all - there could no more be conceptual dance than there could be conceptual visual art, conceptual film or conceptual music. What is more, dance and choreography employ a medium that appears importantly physical in that it typically explores and exploits the corporeality of performers. It seems that dance not only has a physical medium, but a physical medium. How can that be squared with the understanding of conceptual art elaborated through the idea idea? And

\footnotetext{
${ }^{3}$ For example, Xavier Le Roy has declared “I don't consider myself a conceptual artist and I don't know of one choreographer who works in dance without a concept" (Burrows, Le Roy \& Ruckert 2004). Mårten Spångberg's blog in 2010 posed the question "what if there is no conceptual dance?" (Fabius 2012). And "Not Conceptual" was the title of a panel discussion between Bel, Le Roy, Burrows and Cvejić at Siobhan Davies Studios as part of Parallel Voices in 2007 (Protopapa 2009, 9).
} 
what impact does this have for the appropriateness or otherwise of the term "Conceptual Dance" in designating a particular mode of choreography? ${ }^{4}$

In what follows, I will address these questions, arguing ultimately that there is no category mistake implied by use of the term "Conceptual Dance", but that this does require a reconceptualization of the relation between conceptual art and its physical medium which moves us away from the idea idea. I begin by examining some typical features of conceptual art and by offering a more detailed characterisation of the idea idea as a way of accounting for those features. I then explore whether and how similar features characterise works of so-called Conceptual Dance, before probing further the nature of the physical medium in dance and choreography. I consider the supposed dematerialization of the art object in conceptual art in the context of the experiential encounters through performance offered by Conceptual Dance. Finally, following Julian Dodd's (2016) suggestion that conceptual art is better understood as a genre than as an art form, I argue that the term "Conceptual Dance" does indeed make sense as designating a particular mode of contemporary choreography. This fact prompts reconsideration of role of the physical medium in conceptual art more generally.

Conceptual art and the "idea idea"

The idea idea is developed through reflection on a number of features that Goldie and Schellekens identify as typical of conceptual art. Note that by "conceptual art" they mean not just work made in the heyday of the Conceptual Art movement of the late 1960s and early 1970s, particularly in new York, but also earlier and subsequent art that is similarly motivated (their examples include Marcel Duchamp's readymades and recent work like Santiago Sierra's Space Closed by Corrugated Metal, 2002, as well as work by Joseph Kosuth, John Barry and Vito Acconci). The features identified are not deemed by Goldie and Schellekens to be definitive of conceptualism (they are neither individually necessary nor jointly sufficient). Rather, these features are often associated with it.

Firstly, conceptual artworks are typically self-reflective: they pose questions about, and comment on, the nature of art rather than taking the concept for granted. Duchamp's Fountain, for example, asks "how can something like a urinal be a work of art" and "how can the person who submitted this to an exhibition claim to be the 'artist' when he has participated so little in its making?" (Goldie and Schellekens 2010, 13). Fountain also exhibits a degree of irony and playfulness in challenging what is traditionally accepted as art and the definition of art one might distill from that acceptance. These two features help make the conceptual artwork an "enacted thought experiment, set up to challenge the accepted boundaries of the concept of art" (ibid., 15). Another typical feature of conceptual art is its rejection of medium specificity and troubling of the idea that a physical medium

\footnotetext{
${ }^{4}$ Clearly, dance can be described as conceptual (with a small " $c$ ") when it starts from, conveys or embodies concepts or ideas in some way (which seems to be true of pretty much all dance). My concern here is with a stronger notion of Conceptual (with a capital " $\mathrm{C}$ ") Dance, which relates it to the strategies and preoccupations of Conceptual Art. Some question whether the coining of the term was informed by knowledge of this artistic movement (Cvejić 2014 [2005], 145). The term's subsequent use, and the surrounding controversy, is clearly shaped by its evocation of Conceptual Art, however.
} 
is necessary to art at all. Conceptual art employs diverse physical media. Duchamp's readymades are created from found objects. Joseph Kosuth's (1966) '(Titled Art as Idea as Idea), [Water]' exhibits a negative photostat of a dictionary definition of water. Robert Barry's Inert Gas: Helium involved Barry releasing small amounts of helium (an imperceptible material) in a California desert on a single day in March 1969. Barry's All the things I know but of which I am not at the moment thinking, 1.36 pm June 15, 1969, meanwhile, consists of these words displayed on a wall. And Vito Acconci's Following Piece (also 1969) was described by him as an: "Activity, 23 days, varying durations. Choosing a person at random, in the street, any location, each day. Following him, wherever he goes, however long or far he travels. (The activity ends when he enters a private place - his home, office, etc.)." This eclecticism in the kinds of objects employed by conceptual artists creates a sort of general ontological insecurity: it can be unclear where works begin and end because anything could be part of them (or not). And in cases like Following Piece, it is unclear whether the work is the set of instructions, the repeatable action these instructions specify, the event(s) that fulfilled them or the documentation of the activity exhibited on gallery walls (including typed pages, handwritten notes and photographs of staged re-enactments of the activity which occurred some time after the event described). ${ }^{5}$ Conceptual art also provokes an epistemological crisis: how can the viewer tell what is art and what is not once art routinely involves perfectly ordinary, uncrafted objects or actions? And how should she respond?

Finally, Goldie and Schellekens describe the anti-aesthetic impulses of conceptual art, the fact that its artists often refuse to present the audience with an object that can be aesthetically appreciated. In some cases, the object put forward is not the kind of thing that normally provokes an aesthetic response. Or responding aesthetically to it seems to be beside the point of the work (the urinal in Fountain; the glass of water on the shelf in Michael Craig-Martin's An Oak Tree, 1973). In other cases, there is apparently no object to appreciate because the art is fully dematerialized: Acconci's Following Piece or Barry's All the things are cited as possible examples here (Following Piece will be discussed further below). According to the idea idea, there may be physical objects we engage with in order to access the work, but these seem like adjuncts or peripheral elements rather than a focus of appreciation in their own right. This problematizes the idea that direct perceptual encounter is central to art appreciation. Indeed, Duchamp describes the aim of the sentences inscribed on his readymades as follows: "[ $t$ ]hat sentence instead of describing the object like a title was mean to carry the mind of the spectator towards other regions more verbal" (cited in Godfrey 1998, 27-8). Goldie and Schellekens write of how appreciation of conceptual art is "discourse dependent": the viewer needs know background information to understand or engage with it, and this information that is not directly accessible via perceptual encounter with the work (Goldie and Schellekens 2010, 29-33). Joseph Kosuth's One and Three Chairs, for example, depends for its appreciation on knowledge of Plato's metaphysics, and Kosuth asserts that "the very stuff of art is indeed greatly related to 'creating' propositions" (cited in Goldie and Schellekens 2010, 31).

According to Goldie and Schellekens, these features point towards the "idea idea": a way to articulate the fundamental motivation of conceptual art and to explain its challenge in relation to traditional modes of art-making and appreciation. The central thought of the idea idea is that, in

\footnotetext{
${ }^{5}$ These materials are also available to view on Acconci's website: http://www.vitoacconci.org/. Following Piece is listed under Photo/Text works.
} 
conceptual art, ideas themselves become the artistic medium. This is in contrast to traditional art, which involves the artist working a physical medium (oils on canvas, say) until it adequately expresses what she wants to say. The audience of traditional art perceptually engages with the medium manipulated by the artist in order to appreciate the crafted work and understand its artistic statement. But in conceptual art, it is claimed, "there is no physical medium: the medium is the idea" (Goldie and Schellekens 2010, 33). The artist works with ideas, manipulating materials as the means whereby those ideas can be communicated, but without focusing on the crafting of those materials as such. Sol LeWitt, for example, claims that "all of the planning and decisions are made beforehand and the execution is a perfunctory affair", whilst Kosuth urges that conceptual artists "work with meaning, not with shapes, colours or materials" (both cited in Goldie and Schellekens $2010,34,56)$. The viewer engages not (or not so much) with the sensory surface of the work and the detail of its crafting, but with the ideas that it communicates. Whatever physical presence the work has, this functions simply as means of access to those ideas, not as the focus of appreciation.

The challenge(s) of conceptual dance

Self-reflectiveness and irony are features of so-called Conceptual Dance too. The work of Bel, Le Roy and others is typically presented in dance venues, festivals and programmes, but it questions audience expectations concerning what dance is and might be. As described the beginning of this essay, Jérôme Bel confronts spectators with minimal movement as the dancers walk from one area of the stage to another, write on the back wall in chalk and draw one another's bodies with lipstick. The movement as such is unremarkable, even if some of the actions performed are surprising. When the performers pull at, stretch and distort the shape of their own flesh, the viewer's focus is on weird, sometimes comic images generated, not so much on how the dancers move to achieve this end. This poses a challenge to traditional expectations of dance, vividly illustrated by the much discussed lawsuit brought against the Irish International Dance Festival by Raymond Whitehead, a member of the work's audience. Whitehead sued the festival for false advertising, arguing that "[t]here was nothing in the performance he would describe as dance, which he defined as 'people moving rhythmically, jumping up and down, usually to music but not always' and conveying some emotion" (Holland 2004; Bauer 2010b; Lepecki 2006). Although the case was dismissed, the judge was sympathetic to the claimant and the Festival ordered to pay legal costs.

Whilst similarly self-reflective, other works by Bel are perhaps more obviously ironic. The Show Must Go On (2001), for example, is structured around a sequence of eighteen pop records, with the action on stage presenting a series of literal embodiments of the different songs' lyrics. The work begins in darkness, as the audience sits through several minutes of "Tonight" from West Side Story. The lights go up on the empty stage to the song "Let the Sun Shine" from the musical Hair. The performers arrive on stage to The Beatles' "Come Together" and start dancing frenetically with each iteration of the chorus in David Bowie's "Let's Dance". And so on. The work is playful, humorous and surprising, despite the fact that the rules of its game become clear relatively quickly. It offers an ironic and knowing reflection on what is expected of dance art within the theatre frame, on the relation between music and dance, and on compositional structure in choreography. 
As the above examples suggest, the choreography of Bel and his contemporaries also questions the traditional medium of dance, avoiding recognisable dance techniques and the display of virtuosic bodies skilfully performing them. Although Bel's work has a recognisable style, it also refuses the modernist imperative of inventing a new idiosyncratic movement idiom as the vehicle for his artistic expression. And rather than focusing primarily on the body in movement as choreographic material, a range of other elements is also employed. In Bel's first work, Nom donné par l'auteur (1994), two dancers sit facing one another handling a series of objects and constructing "sentences" by sequencing them in particular ways. Bel comments: "[c]hoosing to use objects, the absence of any conjuring, and restraining our presence on stage to a maximum were part of a strategy which made it possible for choreography to appear where paradoxically there would not even be a hint of the least dance step!". This produced a "skeleton of a dance show: a choreography-skeleton devoid of its dance-flesh" (in Lepecki ed. 2012, 73). Conceptual Dance also often involves the dancers speaking, a potentially radical strategy in an art form conventionally considered non-verbal. ${ }^{6}$ In Bel's works for solo dancers (Véronique Doisneau, Cédric Andrieux and Lütz Forster, for example) and in the duet Pichet Klunchun and Myself, dancers narrate stories of their lives, past experiences, hopes and disappointments, interspersed with demonstration of movement sequences quoted from a variety of sources. Xavier Le Roy's Product of Circumstances - an auto-biographical solo along similar lines - appears more like an academic lecture than a traditional dance performance. Vera Mantero articulates the eclecticism of materials used by her choreography when she describes her preoccupation with incorparting new tools into dance to enable it to say more: "I went for the voice, for the word, for actions that are not necessarily dance, for other kinds of activities that could be done on stage. I went for objects" (in Lepecki ed. 2012, 77).

So-called Conceptual Dance has its anti-aesthetic dimension too. The dancers' movements and the choreographer's skill in manipulating a pre-existing or idiosyncratic new movement idiom are no longer sources of aesthetic pleasure. Whitehead's reaction to Jérôme Bel articulates his shock at being confronted with nudity, pedestrian movement and on-stage urination rather than rhythmic or expressive movement synchronised with music. In The Show Must Go On, the shaky attempts of the women performers to dance ballet enchaînements (to the accompaniment of Lionel Richie's " $\mathrm{A}$ Ballerina Dream") challenge any expectation of aesthetically luxuriating in virtuosic performance (although the earnestness and vulnerability of the dancers remains quite touching). Disabled Theater, meanwhile, involves members of the Swiss performance group Theatre Hora introducing themselves and then performing dances of their own devising. They discuss how Bel has selected the dances to be performed on aesthetic grounds. Then those dancers whose solos were not chosen voice their disgruntlement at Bel's judgments. The announcer, who sits at the side of the stage throughout, detailing the instructions given by Bel to the performers, subsequently explains that the choreographer - confronted with the dancers' complaints - decided that the 'rejected' solos should be shown after all, and each of these dances is then performed. The work wears on its sleeve its own

\footnotetext{
${ }^{6}$ In fact, combining speaking and dance has a long history, and is evident in twentieth century practice in, for example, Pina Bausch's Tanztheater. So this is not an innovation specific to Conceptual Dance.
} 
strategies of construction and explicitly undoes itself as a composition. But it also explicitly challenges aesthetic judgment as a valid ground on which to construct staged choreography. ${ }^{7}$

So at least some works of so-called Conceptual Dance have features in common with conceptual art as characterised by Goldie and Schellekens (2010). But there are also dissimilarities, cited by some commentators as reasons to reject the label. This work does not withdraw from the perceptual, replace the perceptual with the linguistic or dogmatically prohibit physicality (Cvejić et al., 2014 [2005], 50). And although "what is beautiful about such works is often the clarity and simplicity of their underlying conceptual structures or [...] key ideas", they still insist on the performer's physical presence and foreground the materiality of performance (Burt 2017, 9-12). Given the apparent interest of these choreographers in the physical medium they employ, it is unclear that the idea idea - with its insistence on ideas as the medium of conceptual art - can apply in this context. In any case, it is not obvious that there could be such a thing as Conceptual Dance, since the term indicates precisely the sort of medium specificity that conceptual art rejects.

There are three possible responses to this quandary. (1) Assuming that the idea idea is right, one might argue that so-called Conceptual Dance collapses into conceptual art generically conceived: this would involve finding a way to explain away these choreographers' apparent engagement with a physical medium, to show that they actually work with ideas. Bodies in movement, choreographed action or however else the medium of dance is characterised (more on this below) then become merely the means by which those ideas are communicated, not a focus of appreciation in themselves. (2) Alternatively, still assuming the idea idea is right, one might argue that so-called Conceptual Dance turns out, on reflection, to be too reliant on its physical medium to qualify as conceptual art. In this case, consideration of the idea idea helps show how the work of the choreographers mentioned is in fact more traditional than its designation implies - or, at least, that its radicality does not reside in its challenges to the dance medium. (3) Finally, one might hold that the idea idea is wrong to claim that conceptual art does not exploit a physical medium (rather than mere physical means) and that there is therefore no barrier to accepting different types of conceptual art according to the art forms that provide their contexts of generation. In what follows, I will explore the reasons to prefer this third option, probing further the physical medium of dance and choreography, to make a case for the possibility of Conceptual Dance.

Physical medium, means and artistic mediation

What is the physical medium of dance or choreography? Posing the question in this way implies that "dance" and "choreography" are synonyms, that they are different ways of designating the same art form. An alternative view would be that dance is the physical medium of choreography: choreographers shape the movement dancers perform, determining its parameters in order to articulate an artistic utterance of some kind. Conceptual Dance questions this understanding of the choreographic medium. As we have seen, it often rejects dance, or at least dancing in the sense of

\footnotetext{
${ }^{7}$ See Siegmund (2017), 15-28, for an illuminating discussion of how Bel's work disrupts modernist dance aesthetics.
} 
performing inventive, expressive and virtuosic movement shaped by choreographic purpose. ${ }^{8}$ Here, it seems, choreography and dance pull apart: there can be choreography without dance, choreography that finds other means of physicalisation (objects, words, different formats of presentation, say). In fact, this idea is not specific to those artists typically associated with the term "Conceptual Dance". William Forsythe works outside of this frame and yet his "choreographic objects" are attempts to explore whether it is "possible for choreography to generate autonomous expressions of its principles, a choreographic object, without the body" (in Spier ed. 2011, 90). ${ }^{9}$ Indeed, the pulling apart of choreography and dance within the art form is arguably part of a wider trend towards expanding the notion of choreography (Allsopp and Lepecki 2008; Protopapa 2013). This trend is evident in the wider culture too. Although coined in the eighteenth century to mean the writing of dances, then morphing into a term for dance composition, the word "choreography" now "enjoys widespread use as referent for a structuring of movement, not necessarily the movement of human beings", with buildings, cameras, multiprotein complexes and web services variously described as choreographing (respectively) space, cinematic action, DNA repair and interfaces (Foster 2011, 2).

So-called Conceptual Dance questions the medial function of dancing in relation to choreography, whilst also interrogating the idea that movement is the physical medium of dance. Conventional movement techniques and dance vocabularies that elsewhere function as choreographic resources are abandoned or critiqued. But there are also challenges to the idea that dance is necessarily imbricated with movement at all. André Lepecki argues that, in the work of Bel, Le Roy and Mantero (amongst others), dance is "exhausted": stillness, stuttering and fragmentation function to disrupt the isomorphism of dance and movement and thereby also the "kinetic ontology of modernity"; Conceptual Dance presents a radical socio-political as well as aesthetic challenge by interrupting dance's "being in flow" (Lepecki 2006, 6). Similarly, Vera Mantero comments on her search for meaningful choreography bypassing the demand for constant movement: "dance had this eternal flailing, all the time agitating one's arms, and that did not seem to say anything" (in Lepecki ed. $2012,77)$. Her own interest was in a mode of performance that was "[l]ess exhibitionistic, less gesticulating, less superficial. [...since] [t]he principle of staying in eternal flailing leads us nowhere" (ibid., 78). Hence the wider range of tools employed in her choreography, noted above, but also her interest in exploring states of immobility. ${ }^{10}$

In the dance philosophical literature, there is in any case debate about whether it is appropriate to characterise the physical medium of dance (or choreography) as movement. Much of this literature predates, or discusses work that predates, the advent of Conceptual Dance, although it does

\footnotetext{
${ }^{8}$ The terms "non-dance" and "anti-dance" have also been applied to the work of the choreographers discussed here (see, for example, Frétard 2004).

${ }^{9}$ See, for example, the installations Scattered Crowd (2002) and Fact of the Matter (2009) (further details on https://www.williamforsythe.com/installations.html), as well as the web resource Synchronous Objects (https://synchronousobjects.osu.edu/).

${ }^{10}$ Of her interest in immobility in performance, Mantero suggests: "[i]t is very important not to understand immobility as a choice to refuse movement. As if movement does not interest me. It is nothing like this. On the contrary: it is because I am so interested in dance, so invested in finding a dance that makes sense to me" (Lepecki 2012, 78). The investment of conceptual choreographers in dance as art form or medium is discussed further below.
} 
sometimes comment on Judson Dance Theater and the work of proto-conceptual choreographers such as Yvonne Rainer (Carroll and Banes 1982, Davies 2004a and 2011). Arguably, dance in general is more appropriately conceived as working with action than with movement. Monroe Beardsley, for example, writes: "I believe (with Beiswanger) that dancing consists not in (what Katchadourian calls) movements, i.e. motions, but in actions generated by them" $(1982,32)$. In certain contexts, bodily motions are transformed into "movings" and "posings", basic bodily actions sortally generating dance action. Similarly for David Carr (1987) and Graham McFee $(1992,2018)$, dance is action not mere physical behaviour: its significance depends on the agency of performers and choreographers, and on the intentional context in which it is developed. And both Beardsley and McFee stress how "there is nothing in the nature of motions themselves that mark off those that can be dance from those that cannot: practically any kind is available" (Beardsley 1982, 32; McFee 1992, 49). These insights can be developed in an ontological direction to challenge received views about choreographic materials being movement or moving bodies (Pakes forthcoming). If the medium of choreography is action, then it seems that choreographers (or at least those choreographers producing performable works) work with repeatable structures of action, that is with action-types organised into a pattern. If choreographers work with action-types, then their medium is abstract rather than physical, or physical only in the extended sense that the tokenings of these types (and not the types themselves) are physical things. ${ }^{11}$

This points to a more general set of issues about the notion of a physical medium. For many philosophers, the physical materials of art are non-identical to the artistic medium with which the artist works. Joseph Margolis draws a distinction between physical medium and artistic medium (Margolis 1980), whilst David Davies contrasts vehicular and artistic medium (Davies 2004a and 2004b). Where the physical medium of painting might be oils and canvas, for example, its artistic medium is the system of brushstrokes whereby those materials are manipulated to create the finished work. In dance, the contrast might be drawn between bodily movements and articulated steps (Davies 2004a, 56). It is not just the physical stuff of which art is made but also conventions of the art form that play a role in mediating artistic content. The medium thereby "relates the work's perceptible properties to the agency of a maker whose purposeful composition in that medium is a source of those properties" (Davies 2004a, 57). And working in a medium involves "the conception of a work by its maker as being a work of a certain kind" (Lamarque 2010,40 ). This is relevant to socalled Conceptual Dance insofar as at least some of the ideas explored by Bel (for example) only make sense if we think of what he is doing as coming from dance. This can only be self-reflective dance if is already dance in some sense, however avant-garde, radical or opposed to certain conventional modes of choreography.

Whether one characterises the physical medium of choreography as the body, movement or action, these means are not specific to this art form. They are also in play in theatre (conceived as performance rather than literature), particularly physical theatre, as well as body art and performance art, for example. Indeed, one of the interesting features of so-called Conceptual Dance

${ }^{11}$ Thus, Julian Dodd argues that artworks that are types can still be in a physical medium: musical works use the medium of sound - their tokens are sound events and sound is how they transmit their content, so they are physical "in an extended sense" (Dodd 2016, 248). 
is its visible affinity with these different art forms as it extends the kinds of action that it stages. The performers' manipulation of their flesh in Jérôme Bel, for example, recalls the way the body is literally reshaped by some body art practices, with that process of alteration presented for appreciation. Nonetheless, it seems that Bel's work remains choreography not body art, because it still stages the body in action, and conveys its artistic statements through that action's organisation. Arguably, then, this choreography still operates in relation to dance conventions, and needs to in order to make the kinds of statement that it does. Perhaps the work itself draws attention to the fact that these physical materials might have different characteristic applications, exploiting the techniques of neighbouring art forms whilst continuing to frame itself in other respects as dance or staged choreography. So-called Conceptual Dance, then, might reject medium specificity but not the idea of working with a physical medium as such.

Dematerialization, ontology and perceptual encounter

According to the idea idea, conceptual artists work with ideas rather than a physical medium. The logical extension of this thought is that the works they produce are also ideas rather than physical things, even if they require some sort of physical presence to be communicated. This is one way to understand what Lucy Lippard famously described as Conceptual Art's "profound dematerialization of art, especially of art as object, [which] if it continues to prevail, may result in the object's becoming wholly obsolete" (Lippard and Chandler, 1968, 36). With many conceptual artworks, "we seem to have no object to appreciate": the various physical things (readymade objects, photostats, photographs, texts on gallery and urban walls, and so on) that stand proxy for the work appear as "the mere means by which we grasp the artist's ideas", not objects of appreciation in their own right (Goldie and Schellekens 2010, 76). But it is not clear that the objecthood of conceptual artworks dissolves as completely as the idea idea indicates, nor that the ontological position which maintains that artworks are ideas is sustainable. One might, on the one hand, probe the ontology of ideas to question whether artworks can indeed be ideas (Cray 2014, Cray and Schroeder 2015). On the other hand, one might question the assumption that the different mode of appreciation required by conceptual art in comparison with traditional art necessarily also implies a distinct ontology (Dodd 2016). Dodd suggests that conceptual art does not in fact challenge our "folk" ontology of art, which holds that works are either physical objects, events or types of event. For each of the examples that Goldie and Schellekens present, Dodd claims, there are plausible candidate objects with which these conceptual artworks might be identified, and which fall into one or other of these "folk" ontological categories.

In the present context, one contested example in particular is instructive - Vito Acconci's Following Piece (1969), which (as noted earlier) is described by Acconci as follows: "Activity, 23 days, varying durations. Choosing a person at random, in the street, any location, each day. Following him, wherever he goes, however long or far he travels. (The activity ends when he enters a private place - his home, office, etc.)." Goldie and Schellekens propose two different interpretations of this work and how it relates to dematerialization. The first view holds that (1) Following Piece is a performance and an instance of Performance Art. This implies that "performance is the medium whereby we come to appreciate the work" as it is in performances of Beethoven's Violin Concerto in D major by Frank Peter Zimmerman and of Kenneth Macmillan's Manon by Agnes Oaks. Where these other 
works are concerned, "the precise way the performance is performed matters in our artistic appreciation of the work" as "we are influenced by the most subtle of changes to the way the Beethoven is played or the way the dance movements are performed in Manon" (2010, 76-7). On this view, how Acconci performed the activity described makes a difference to what the work says to its audience. The second view (which Goldie and Schellekens prefer) is that (2) Following Piece is an instance of conceptual art rather than performance art. This would understand the performance or event as mere means rather than medium: "the precise way the performance is performed matters no more to our appreciation than does the precise way the goatee beard is drawn in Duchamp's $\angle H O O Q^{\prime \prime}(78)$. Moreover, the work could not be performed at all, yet still exist and be appreciated as the idea that it is. On this view, the existence (or past occurrence) of an event embodying the activity described by Acconci is irrelevant to the existence of the work and the point it seeks to make. Reasons to prefer this second view include the fact that the audience has very little to go on when trying to engage with Following Piece: just a few staged photos and Acconci's description. This suggests that the detail of its performance does not matter to its artistic statement.

The irrelevance of the performance element does not follow from the fact of partial documentation. After all, plenty of works in the history of dance have only very patchy documentation, but that does not demonstrate that their performance was therefore unimportant for their appreciation. What Goldie and Schellekens must mean here is that engaging with a description of Acconci's work is adequate for appreciation, and that our understanding is not significantly enhanced by perceiving the event or staged photographs of its re-enactment. This, they claim, is borne out by contrasting Following Piece with other works by Acconci that are appropriately understood as performance art. Adaptation Studies consists of three performances by Acconci in 1970, filmed by an "accomplice", titled "Blindfolded Catching", "Soap and Eyes" and "Hand and Mouth". In these films, Acconci (respectively) sits blindfolded as he is bombarded with rubber balls, throws a bowl of soapy water in his own face and then tries to keep his eyes open; and sticks his fingers down his throat. The suggestion is (although this is not elaborated explicitly) that the spectacle of Acconci being bombarded with balls, the faces he pulls whilst struggling with the soap in his eyes, and his body movements as he gags on his own hand, matter to appreciation. They are a focus of appreciation, whereas the details of the physical event in Following Piece are not.

Dodd takes issue with this. He agrees that Acconci's words describe a particular event (rather than being a set of instructions identifying a type of event), but argues that this event is the obvious candidate for being the work. We cannot directly perceive it anymore, "but it does not follow from this that this the dated and located event is in any way categorially unsuited to be the work" (Dodd 2016,246 ). Dodd also agrees that we do not need to encounter the event perceptually in order to appreciate Following Piece because its conceptual subject matter is more important than the details of the performance. We can still "sensorily imagine" the work, however, enabled by the photographs. And, according to Dodd, it is important to appreciation that the event did in fact take place. "This is because appreciating this work requires us to grasp certain of its properties that it can only have - or plausibly only have to the extent intended by Acconci - if physically embodied" (Dodd 2016 , 251). The work, for example, is eerie, one of the things that captures audience attention being "the sheer creepiness of someone's following random people in the street, however far they travel" (ibid.). But Following Piece does not have this property if Acconci merely has the idea of behaving 
thus, rather than actually putting the idea into practice. The performance is necessary if the work is to realise its utterance and effect.

A similar argument can be rolled out in relation to works of Conceptual Dance. The activity of urinating on stage in Jérôme Bel is shocking, and the embodiment of pop song lyrics in The Show Must Go On playful. But these qualities are not realized unless the activities are actualized on stage. Merely having and communicating the idea to do these things is not enough. And we might go further than Dodd in arguing that the perceptual encounter (particularly its durational aspect) really matters to Conceptual Dance. Bel cannot make his points about the theatre and the theatrical contract between performers and spectators without performers and spectators physically occupying the same space for a specified duration. He could verbally outline his questions about the reasonableness of expectations set up by the theatrical frame, about the power dynamics and semiotic procedures of the theatre, about the relation between high art and popular culture, and so on. But it is only through their embodiment that these points are properly made. They are pressed through the experience furnished by the theatrical encounter.

Pichet Klunchun and Myself presents a further example. This piece choreographs and stages a dialogue between Jérôme Bel and the Thai dancer and choreographer, Pichet Klunchun, who practices the traditional dance form of Khon. The work again offers a reflection on the nature of dance and audience expectations thereof, but here in a cross-cultural perspective, thematising also the relation between East and West under postcolonialism. The disparity and inequality of the relation is brought home by the spatial arrangement of the performers, and the unfolding choreographic structure. In the first half of the show, Bel asks a series of questions of Klunchun, who answers matter-of-factly, periodically rising from his chair to demonstrate sequences of movement in illustration. Bel sometimes queries or comments critically and humorously on Klunchun's answers, whether they are verbal or danced, adopting the attitude of the naïve, slightly supercilious Westerner trying - and often struggling - to understand a practice and a mindset that emerges from a very different artistic and cultural context to his own. Midway through the performance, the tables turn and Klunchun adopts the role of interviewer, criticising Bel for the recalcitrance of his answers and exhibiting a similar lack of comprehension for aspects of his work and lifestyle. Even if the protagonists, at certain moments, establish a mutual acknowledgement and sympathy, their dialogue is also sometimes tense, uncomfortable, revealing of a cultural chasm or fundamental inequality. Differences are highlighted and reflected upon but not necessarily reconciled: the pace and rhythm of the work mean that the viewer feels the discomfort physically. Here, the theatrical performance is a means whereby certain ideas are articulated, but does not seem to be mere means in the sense that it might be substituted by something else. This physical vehicle is required to make (and affectively reinforce) the particular ideas being expressed. And the audience must engage with the physical vehicle (the performance) to fully grasp them. ${ }^{12}$

\footnotetext{
${ }^{12}$ For further discussion of Pichet Klunchun and Myself, see Foster (2011), Hardt (2011), Kwan 2014 and Pakes (2019). At the time of writing, a film of a (2011) performance at the Kaaitheater, Brussels, is available to view on Bel's website: http://www.jeromebel.fr, in the section entitled "videos". My description of the work is based on viewing this film (by Aldo Lee and Jérôme Bel).
} 
There is, of course, a certain irony here in my attempt to offer sufficiently vivid descriptions of dance works to convey the importance of perceptual encounter, whilst simultaneously making these descriptions stand as proxies for actual experiences of the works (at least for those readers who have not seen them). It is as if the performative operation attempted by my writing itself undercuts the claim that these works cannot be properly appreciated through their verbal description. ${ }^{13}$ This claim also seems compromised by some of Bel's own practice, particularly his substitution (between 2004 and 2010) of an artist's talk called The Last Performance: A Lecture for a performance of the (1988) work The Last Performance. Efrosini Protopapa describes the start of Bel's talk (as delivered at Sadler's Wells Theatre, London, in February 2008), where he justified the decision on the grounds that the work itself had been unsuccessful and boring, despite the enduring interest of its underpinning ideas: "he hoped that these ideas could potentially be interesting for an audience, if only he could communicate them in a different format; hence he chose the set-up of what he called a lecture demonstration" (Protopapa 2013, 279-80). But it is not obvious that Bel's comments here should be taken at face value. The theoretical ideas explored in the talk only partly reflect the content of The Last Performance, and Protopapa makes a persuasive case for the lecture performance itself being a new work, one which offers a staging of the persona of Jérôme Bel himself and a playful reflection on the expanded notion of choreography (ibid., 280-284). Perhaps it also reflects on the relation between words and the performative or perceptual encounter offered by conceptual art/dance, as Bel has done in print too. In email conversation with fellow choreographer, Boris Charmatz, Bel asserts that a conceptual dance is "a text, some words that indicate a dance", but goes on to query the label "Conceptual Dance" on the following grounds: "for the time being, we have never been able to reduce dance simply to an idea. We are still encumbered by these stinking and aching bodies stuffed with emotions" (Bel and Charmatz, cited in Siegmund $2017,67)$. The trajectory of Bel's choreographic career, and the kind of work that he continues to make for the theatre, suggest that he uses the word "encumbered" here partly with tongue-in-cheek - that he has no intention of abandoning the kind of perceptual encounter enabled by the theatrical frame.

\section{Conclusion}

Conceptual Dance, then, still deals in staged action and its appreciation still requires perceptual encounter. In this sense, the choreography associated with the term employs a physical medium, albeit a physical medium "in an extended sense" (Dodd 2016, 248, and see above). Consequently, Conceptual Dance presents no particular ontological challenge: its works (insofar as they are multiply performable) still seem to be structures of actions, or types of which there can be numerous performance tokens which realise those actions physically. ${ }^{14}$ This kind of choreography may make rather different demands of audiences to those posed by the modernist and

\footnotetext{
${ }^{13}$ This also raises a general issue which cannot be addressed here, about the problem of verifying (or falsifying) claims made in discussions of dance works that are not routinely re-performed or adequately documented.

${ }^{14}$ This commonly held view of the ontology of dance works might, of course, be challenged. But, on the argument here, such challenges would pertain to dance works in general, and not just works of Conceptual Dance. See Pakes (forthcoming) for more detailed discussion of the ontology of dance works.
} 
postmodernist work it reacts against. If nothing else, it forces reflection on what is expected of the physical aspect of dance, and on how this physical aspect is related to the artistic utterance. But there is still a physical medium. Or, taking on board the insights about medium explored above, there is still an artistic medium related intimately to its physical embodiment.

One might argue (like Bel above and Cvejić 2014 [2005]) that, because Conceptual Dance relies on performance and the perceptual encounter enabled by it, the label "Conceptual Dance" is inappropriate. Returning to the possible responses to the question "Can there be Conceptual Dance?" outlined above (see end of section 2), this would be to reject option (1) - Conceptual Dance is not in fact conceptual art made by choreographers - and plump for option (2) - for all its radicalism, so-called Conceptual Dance remains medium-focused and therefore is not characterised by the dematerialization central to conceptual art. But I think option (3) remains preferable. The term "Conceptual Dance" encourages us to revisit the practice and underpinning motivations of conceptual art, and to question their articulation in terms of dematerialization and the idea idea. It seems to me that many works of conceptual art have important properties that depend on their physical embodiment in either a thing, an event or multiple occurrences. For example, one of the reasons that Fountain endures and still has affective power (despite the reams of explicative philosophical writing about it) is arguably that coming across an upturned urinal on a visit to the gallery is still surprising. The nature of the object, as well as its context and framing, is central to that effect. It seems that the means of many conceptual artworks have a medium-like role to play, insofar as the physical stuff matters to what the idea is as well as how it is conveyed.

So, can there be Conceptual Dance? Yes, if conceptual art is understood as a genre rather than an art form, and thereby as a mode of dance rather than as a branch of an art form that eschews the physical. This builds on the distinction drawn by Julian Dodd between art form and genre: whereas an art form determines the media of a work's production, "assignment of a work to a genre tells us, not why its creator employed certain artistic technologies and not others, but something about the purpose with which it was made and in terms of which it is to be appreciated and evaluated" (Dodd 2016, 257). Following Duchamp, Dodd suggests that this purpose is to "transport us to regions more verbal than aesthetic" (ibid., 258). The ideas examined in Conceptual Dance may often be such as to exceed or resist verbal paraphrase, as the choreography thinks through rather than circumventing physicality. Nonetheless, the assertion of intellectual purpose within Conceptual Dance is important because of the longstanding resistance to acknowledging that a corporeally embodied art form can both have and articulate ideas. As Mantero suggests "[t]he principle of staying in eternal flailing leads us nowhere" (ibid., 78). ${ }^{15}$

\footnotetext{
${ }^{15}$ Special thanks to Elisabeth Schellekens for posing the questions that prompted this essay. I am also indebted to the audiences who attended my talks on philosophy and Conceptual Dance at the Centre for Performance Philosophy, University of Surrey (February 2015); the Dance Studies Colloquium at Temple University, Philadelphia (March 2015); the American Society for Aesthetics Eastern Division, Philadelphia (March 2015); and the Higher Seminar in Aesthetics at Uppsala University (December 2015). A fellowship grant from the Arts and Humanities Research Council enabled the wider project on dance ontology of which these talks formed a part, and I am very grateful to the Council.
} 


\section{REFERENCES}

Allsopp, Ric and André Lepecki (2008) "Editorial: On choreography," Performance research, 13:1, 1-4

Banes, Sally (1983) Democracy's Body: Judson Dance Theater, 1962-1964, Ann Arbor, MI: UMI Research Press

Bauer, Una (2010b) "The Movement of Embodied Thought: The Representational Game of the Stage Zero of Signification in Jérôme Bel," Performance Research, 13:1, 35-41

Beardsley, Monroe C. (1982) "What is going on in a dance?" Dance Research Journal, 15: 1, 31-36

Burt, Ramsay (2017) Ungoverning Dance: Contemporary European Theatre Dance and The Commons, New York: Oxford University Press

Carr, David (1987) "Thought and action in the art of dance," British Journal of Aesthetics, 27: 4, 345357

Carroll, Noël and Sally Banes (1982) "Working and dancing: A reply to Monroe Beardsley," Dance Research Journal, 15: 1, 37-41

Cray, Wesley D. (2014) "Conceptual Art, Ideas, and Ontology," Journal of Aesthetics and Art Criticism, $72: 3,235-245$

Cray, Wesley D. and Timothy Schroeder (2015) "An Ontology of Ideas," Journal of the American Philosophical Association, 1:4, 757-775

Cvejić, Bojana (2014 [2005]) "To End with Judgment by Way of Clarification", in Noémie Solomon ed. Danse: An Anthology, Paris \& New York: Les Presses du Réel

Davies David (2004a) Art as Performance, Malden, MA: Blackwell

Davies, David (2004b) “Medium," in Jerrold Levinson ed. The Oxford Handbook of Aesthetics, Oxford: Oxford University Press

Davies, David (2011) Philosophy of the Performing Arts, Malden, MA: Wiley-Blackwell

Dodd, Julian (2016) "The Ontology of Conceptual Art: Against the Idea Idea," in Julian Dodd ed. Art, Mind and Narrative: Themes from the Work of Peter Goldie, Oxford: Oxford University Press, 241260

Fabius, Jeroen (2012) "The Missing History of (Not) Conceptual Dance", in Merel Heering, Ruth Naber, Bianca Nieuwboer and Liesbeth Wildschut, eds. Danswetenschap in Nederland, 7, Amsterdam: Vereniging voor Dansonderzoek. Online at http://www.academia.edu/4060526/J. Fabius. The missing history of not conceptual dance. I $\mathrm{n}$ Merel Heering Ruth Naber Bianca Nieuwboer en Liesbeth Wildschut.Danswetenschap in N ederland deel 7. Amsterdam Vereniging voor Dansonderzoek 2012, accessed $12^{\text {th }}$ March 2015

Foster, Susan Leigh (2011) Choreographing Empathy: Kinaesthesia in Performance, London: Routledge

Frétard, Dominique (2004) Danse contemporaine: Danse et non-danse, vingt-cinq ans d'histoire, Paris: Cercle d'Art

Godfrey, Tony (1998) Conceptual Art, London: Phaidon 
Goldie, Peter and Elisabeth Schellekens, eds. (2007) Philosophy and Conceptual Art, Oxford: Clarendon Press

Goldie, Peter and Elisabeth Schellekens (2010) Who's Afraid of Conceptual Art? London: Routledge Hardt, Yvonne (2011) "Staging the Ethnographic of Dance History: Contemporary Dance and its Play with Tradition," Dance Research Journal, 43:1, 27-42

Holland, Kitty (2004) "Action Against Dance Festival Fails", Irish Times, $8^{\text {th }}$ July (City Edition), 4.

Kwan, SanSan (2014) “Even as We Keep Trying: An Ethics of Interculturalism in Jérôme Bel's Pichet Klunchun and Myself", Theatre Survey, 55:2, 185-201

Lamarque, Peter (2010) Work and Object: Explorations in the Metaphysics of Art, Oxford: Oxford University Press

Lepecki, André (2006) Exhausting Dance: Performance and the Politics of Movement, London: Routledge

Lepecki, André ed. (2012) Dance, London: Whitechapel Gallery and MIT Press

Lippard, Lucy and John Chandler (2000 [1968]) "The Dematerialization of Art", in Alexander Alberro and Blake Stimson eds. Conceptual Art: A Critical Anthology, Cambridge, MA: MIT Press, 46-51

Margolis, Joseph (1980) Art and Philosophy: Conceptual Issues in Aesthetics, Atlantic Highlands, NJ: Humanities Press

McFee, Graham (1992) Understanding dance, London: Routledge

McFee, Graham (2018) Dance and the Philosophy of Action: A Framework for the Aesthetics of Dance, Binsted: Dance Books

Pakes, Anna (2019) "Dance and Philosophy," in Sherril Dodds ed. The Bloomsbury Companion to Dance Studies, London: Bloomsbury, 327-356

Pakes, Anna (forthcoming in 2020) Choreography Invisible: The Disappearing Work of Dance, New York: Oxford University Press

Protopapa, Efrosini (2009) Possibilising Dance: A Space for Thinking in Choreography, unpublished PhD thesis, London: Roehampton University

Protopapa, Efrosini (2013) "Choreography as Philosophy, or Exercising Thought in Performance," in Jenny Bunker, Anna Pakes and Bonnie Rowell eds. Thinking Through Dance: The Philosophy of Dance Performance and Practices, Binsted: Dance Books

Siegmund, Gerald (1998) "Dialogue with the Body (II): In the Realm of Signs - Jérôme Bel”, Ballett International / Tanz Actuell, April, 34-7

Siegmund, Gerald (2017) Jérôme Bel: Dance, Theatre and the Subject, Basingstoke: Palgrave Macmillan

Spier, Steven ed. (2011) William Forsythe and the practice of choreography: It starts from any point, London: Routledge

T’Jonck, Pieter (2004) “Klapstuk \#11 bis: Introduction”, online at http://sarma.be/docs/809, accessed $12^{\text {th }}$ March 2015 
